Article

\title{
Ecological Ammonium Thiocyanate-Modified Geopolymeric Coating for Flame-Retarding Plywood
}

\author{
Yachao Wang * $*$ and Jiangping Zhao \\ School of Resource Engineering, Xi'an University of Architecture and Technology, Xi'an 710055, China \\ * Correspondence: wangyachao@xauat.edu.cn; Tel.: +86-29-82205869
}

Received: 28 June 2019; Accepted: 26 July 2019; Published: 29 July 2019

\begin{abstract}
An ecological ammonium thiocyanate $\left(\mathrm{NH}_{4} \mathrm{SCN}\right)$-modified geopolymeric coating was facilely prepared for flame-retarding plywood. The effect of $\mathrm{NH}_{4} \mathrm{SCN}$ on the flame resistance was preliminarily investigated using cone calorimeter (CC), scanning electron microscope (SEM), X-ray diffraction (XRD), and thermal gravimetry (TG). The results show that $1 \mathrm{wt} . \% \mathrm{NH}_{4} \mathrm{SCN}$ as dopant is of paramount importance to generate a compact and continuous coating. The formation of a smooth, intact, and uniform-swelling siliceous layer during combustion facilitates enhanced fire resistance, evidenced by the increased fire performance index (FPI), reduced fire growth index (FGI), and $39.7 \%$ decreased value of peak heat release rate (pHRR), in comparison to those of the sample without $\mathrm{NH}_{4} \mathrm{SCN}$. Because of the reducibility of $\mathrm{O}_{2}$-consuming $\mathrm{NH}_{4} \mathrm{SCN}$, the compact shielding-layer containing carbonate and sulfate, as well as the release of $\mathrm{NH}_{3}$, the $\mathrm{NH}_{4} \mathrm{SCN}$-modified geopolymeric coating exerts an enhancement on the flame-retardant efficiency.
\end{abstract}

Keywords: flame-retardancy; ammonium thiocyanate; cone calorimeter; thermogravimetry

\section{Introduction}

The organic-inorganic halogen-free hybrid flame-retardant coating has been a hotspot, due to its excellent fireproofing property and ecology, which has become the main developing trend of the coating industry currently [1-4]. This increasing recognition identifies that silica particles offer some advantages including well-defined ordered structures, facile surface modification, and cost-effective preparation [2]. Moreover, inorganic silicate is employed as a physical filler to provide an enhanced barrier effect, and also it serves as a functional filler to enhance the structural strength and adhesion forces [3]. It is also reported to provide an improved anti-aging coating by doping $\mathrm{TiO}_{2}$ and clay nanoparticles [4]. Inspired by a report of inorganic silicate-doped coatings, an exploration of the novel flame-retardant coatings using amorphous $\mathrm{Si}(\mathrm{OH})_{4}$-enriched sol as the binder has been undertaken; these coatings have a self-adhering and cross-linking structure through a facile geopolymerization between the $\mathrm{Si}(\mathrm{OH})_{4}$ and $\mathrm{Al}(\mathrm{OH})_{4}[5]$.

Furthermore, previous investigations have explored the promising application to geopolymeric coating through a facile sol-gel method [6,7]. A novel inorganic coating, the geopolymer serves as a flame-retardant wood primer with a cost-effective edge and has not been widely reported on. Therefore, a multiplication of modification efforts for geopolymeric coatings is necessary to boost a sustainable, ecological, and recyclable economy on a global scale, which holds promising potential and is attracting increasing attention for research and applications. 
In addition, the most prominent bottleneck for inorganic coatings has been identified as the inferior flame retardancy compared to organic coatings, ascribed to lower expansibility and heat absorptivity. To address this problem, phase change materials (PCMs) have been designed in the building envelope as a passive system to reduce heat loss owing to their latent heat storage [8], which also could be used to prepare halogen-free flame retardants $[9,10]$. Consequently, paraffin and expandable graphite (EG) have been used to fabricate hybrid flame retardants [11,12]. The enhancement of the flame resistance of novel geopolymeric coatings modified by a decanoic/palmitic eutectic mixture has been investigated [13].

Moreover, ammonium thiocyanate $\left(\mathrm{NH}_{4} \mathrm{SCN}\right)$, as a kind of solid-solid $\mathrm{PCM}$, can be exploited as solid polymer electrolyte due to its high conductivity and amorphous phase [14]. However, the effect of $\mathrm{NH}_{4} \mathrm{SCN}$ on the flame-retarding property of coatings is a virgin area for hybrid flame retardants. Consequently, this investigation scrutinized the effect of $\mathrm{NH}_{4} \mathrm{SCN}$ on the fire resistance of hybrid geopolymeric coatings using a cone calorimeter (CC). Its microstructure was examined using scanning electron microscopy (SEM), X-ray diffraction (XRD), and thermogravimetry (TG) to preliminarily illuminate its flame-retarding mode of action.

\section{Materials and Methods}

\subsection{Preparation of $\mathrm{NH}_{4} \mathrm{SCN}-$ Modified Geopolymeric Coatings}

\subsubsection{Starting Materials}

The starting material for the geopolymer was gray fumed silica collected by the Linyuan company in Xi'an of China, solid powder derived from silicon-smelting, which had a Blaine specific surface area of $25 \mathrm{~m}^{2} \cdot \mathrm{g}^{-1}$ and a density of $1.62 \mathrm{~g} \cdot \mathrm{cm}^{-3}$. Analysis using X-ray fluorescence (XRF, bruker AXS Co., Karlsruhe, Germany, LTDS4 PIONEER) determined a high silica content (87.46 wt.\%) as shown in Table 1. Analytically pure (AP) $\mathrm{Na}_{2} \mathrm{SiO}_{3} \cdot 9 \mathrm{H}_{2} \mathrm{O}$ and $\mathrm{KOH}$, which served as chemical activators, were purchased from the HongYan reagent factory in Tianjin of China. The modifier $\mathrm{NH}_{4} \mathrm{SCN}$ (AP) was obtained from the FuChen reagent factory of Tianjin in China. Hydrophobic polydimethylsiloxane (PDMS) was prepared by the Tianjin YaoHua reagent factory. The thickener and film-forming agent, polyacrylamide (PAM), was synthesized by the Shanghai reagent factory in China. EG served as the charring fortifier [15] and was fabricated by the Qingdao chemical group in China with a volume-expansion rate of $300 \mathrm{~mL} \cdot \mathrm{g}^{-1}$ and an average particle size of $48 \mu \mathrm{m}$. The second-class flame-retarding plywood was produced in the $\mathrm{Xi}^{\prime}$ an timber processing plant.

Table 1. Compositions of fumed silica tested using X-ray fluorescence (XRF).

\begin{tabular}{cccccccccc}
\hline \multirow{2}{*}{ Material } & $\mathrm{CaO}$ & $\mathrm{SiO}_{2}$ & $\mathrm{Al}_{2} \mathrm{O}_{3}$ & $\mathrm{Fe}_{2} \mathrm{O}_{3}$ & $\mathbf{M g O}$ & $\mathrm{Na}_{2} \mathbf{O}$ & $\mathbf{K}_{2} \mathbf{O}$ & $\mathrm{SO}_{3}$ & Loss \\
\cline { 2 - 10 } & 0.61 & 87.46 & 6.90 & 1.17 & 0.46 & 0.29 & 0.67 & 0.31 & 2.12 \\
\hline Fumed silica & $0.90 i g h t(w t . \%)$ \\
\hline
\end{tabular}

\subsubsection{Preparation of $\mathrm{NH}_{4} \mathrm{SCN}$-Modified Geopolymeric Coatings}

The geopolymeric coatings were prepared by slowly dispersing $50 \mathrm{~g}$ of fumed silica into $200 \mathrm{~mL}$ alkali-activated solution (comprising $1 \mathrm{~mol} \cdot \mathrm{L}^{-1} \mathrm{Na}_{2} \mathrm{SiO}_{3}$ and $2 \mathrm{~mol} \cdot \mathrm{L}^{-1} \mathrm{KOH}$ ) under $60^{\circ} \mathrm{C}$, which was placed on a magnetic stirrer at $60 \mathrm{r} \cdot \mathrm{min}^{-1}$ [6]. After stirring for about $0.5 \mathrm{~h}$, the modifiers including PAM (1 wt. \%), PDMS (1.5 wt.\%), and EG (5 wt.\%) were sequentially added into the aforesaid solution during constant stirring at $60^{\circ} \mathrm{C}$, followed by another stirring for about $0.5 \mathrm{~h}$ [13]. Finally, the $0.5,1,1.5$, 2 , and $3 \mathrm{wt} . \% \mathrm{NH}_{4} \mathrm{SCN}$ was doped into the abovementioned mixture, respectively, the hybrid coating was achieved by another vigorous stirring $\left(1000 \mathrm{r} \cdot \mathrm{min}^{-1}\right.$ for about $\left.15 \mathrm{~min}\right)$. 


\subsubsection{Preparation of Samples}

The samples were the plywood $\left(100 \times 100 \times 4 \mathrm{~mm}^{3}\right)$ covered by geopolymeric coatings after brushing the surfaces three times with an interval time of $40 \mathrm{~min}$. The samples with the $\mathrm{NH}_{4} \mathrm{SCN}$ dosage of $0.5,1,1.5,2$, and 3 wt.\% were denoted as S1, S2, S3, S4, and S5, respectively. Coatings without $\mathrm{NH}_{4} \mathrm{SCN}$ and pristine raw plywood were used as the controls, which were defined as $\mathrm{S} 0$ and Sr. The coating thicknesses were the same, $0.4 \mathrm{~mm}$ approximately.

\subsection{Characterizations}

\subsubsection{Flame Resistance}

The horizontal external heat flux was $30 \mathrm{~kW} \cdot \mathrm{m}^{-2}$ (about $625^{\circ} \mathrm{C}$ for complete decomposition of plywood) to examine the combustion parameters of samples in real time, which was conducted in a CC (ZY6243, Zhongnuo instrument company, Dongguan, China) according to BS ISO 5660-1:2015 [16], the average value was obtained from the three samples with a deviation of $<5 \%$. The heat release rate (HRR), time to ignite (TTI), the peak heat release rate (pHRR), time to $\mathrm{pHRR}\left(T_{\mathrm{p}}\right), \mathrm{O}_{2}$ concentration and smoke temperature in exhaust smoke, and time to the cessation of flaming $\left(T_{\mathrm{b}}\right)$ were recorded in real time. The fire performance index $(\mathrm{FPI}, \mathrm{FPI}=\mathrm{TTI} / \mathrm{pHRR})$ and fire growth index $\left(\mathrm{FGI}, \mathrm{FGI}=\mathrm{pHRR} / T_{\mathrm{p}}\right)$, were the most important indexes to distinguish the flame-retardant efficiency $[7,13,15]$, the sample with a higher FPI and lower FGI corresponded to a stronger flame resistance.

\subsubsection{Microstructure Analysis}

The Quanta 200 SEM (FEI Co., Hillsboro, OR, USA) was employed to observe the micro-morphologies of coating residues after combustion in the CC, the operating voltage was $20 \mathrm{kV}$ with a working distance of $10 \mathrm{~mm}$. The sample with a superficial area of $25 \sim 30 \mathrm{~mm}^{2}$ was placed under a vacuum degree of $<1.33 \times 10^{-3}$ Pa prior to gold sputtering for observation. The D/MAX-2400 $\mathrm{X}$-ray diffractometer with $\mathrm{Cu} \mathrm{K} \alpha$ was used to detect mineral phases of samples, the coating residue was ground into powder for preparing the testing sample with a working voltage of $30 \mathrm{kV}$ and a working current of $40 \mathrm{~mA}$, the scanning speed was $5^{\circ} \cdot \mathrm{min}^{-1}$ with a range of $10^{\circ} \sim 50^{\circ}$. The Mettler thermal balance was exploited to record the TG/DSC values in real time of bare pre-dried sample coatings of about 10 20 mg, which were tested at $50 \sim 200{ }^{\circ} \mathrm{C}$ (the complete decomposition of $\mathrm{NH}_{4} \mathrm{SCN}$ occurred below $180{ }^{\circ} \mathrm{C}$ ) with a heating rate of $5^{\circ} \mathrm{C} \cdot \mathrm{min}^{-1}$ under nitrogen (flow of $50 \mathrm{~cm}^{3} / \mathrm{min}$ ) in an alumina pan.

\section{Results}

\subsection{Flame-Retardant Properties}

The decreased pHRR value for the specimens with $\mathrm{NH}_{4} \mathrm{SCN}$ is presented in Figure 1a, the occurrence of a gradual right-shift indicates a delayed flame propagation, with the increasing content of $\mathrm{NH}_{4} \mathrm{SCN}$. S2 appears to have the lowest $\mathrm{pHRR}$ value of $248 \mathrm{~kW} \cdot \mathrm{m}^{-2}$ with a $39.7 \%$ decrease in comparison to that of $\mathrm{S} 0$, which determines that $\mathrm{NH}_{4} \mathrm{SCN}$ imparts an improved flame resistance to geopolymeric coatings. The combustion process of wood can be divided into four stages, namely, drying, pre-carbonization, carbonization, and combustion, and the HRR property depends on the structural stability of the wood component. The decomposition of wood occurs sequentially as light volatile and partial hemicellulose, hemicellulose, cellulose, and partial lignin [17]. The flame propagation retards or temporarily stops after $80 \mathrm{~s}$, ascribed to surficial charring of plywood [18], with the increasing accumulated heat, the sharply increased HRR indicates a flashover for Sr. However, the curve of pHRR rises when the dosage of $\mathrm{NH}_{4} \mathrm{SCN}$ exceeds $1 \mathrm{wt} . \%$, this indicates that excess $\mathrm{NH}_{4} \mathrm{SCN}$ is detrimental for obtaining an excellent flame retardancy, implying that an appropriate dosage of $\mathrm{NH}_{4} \mathrm{SCN}$ is beneficial to constitute an advantageous fire resistance, the reason is illustrated in Section 4. 

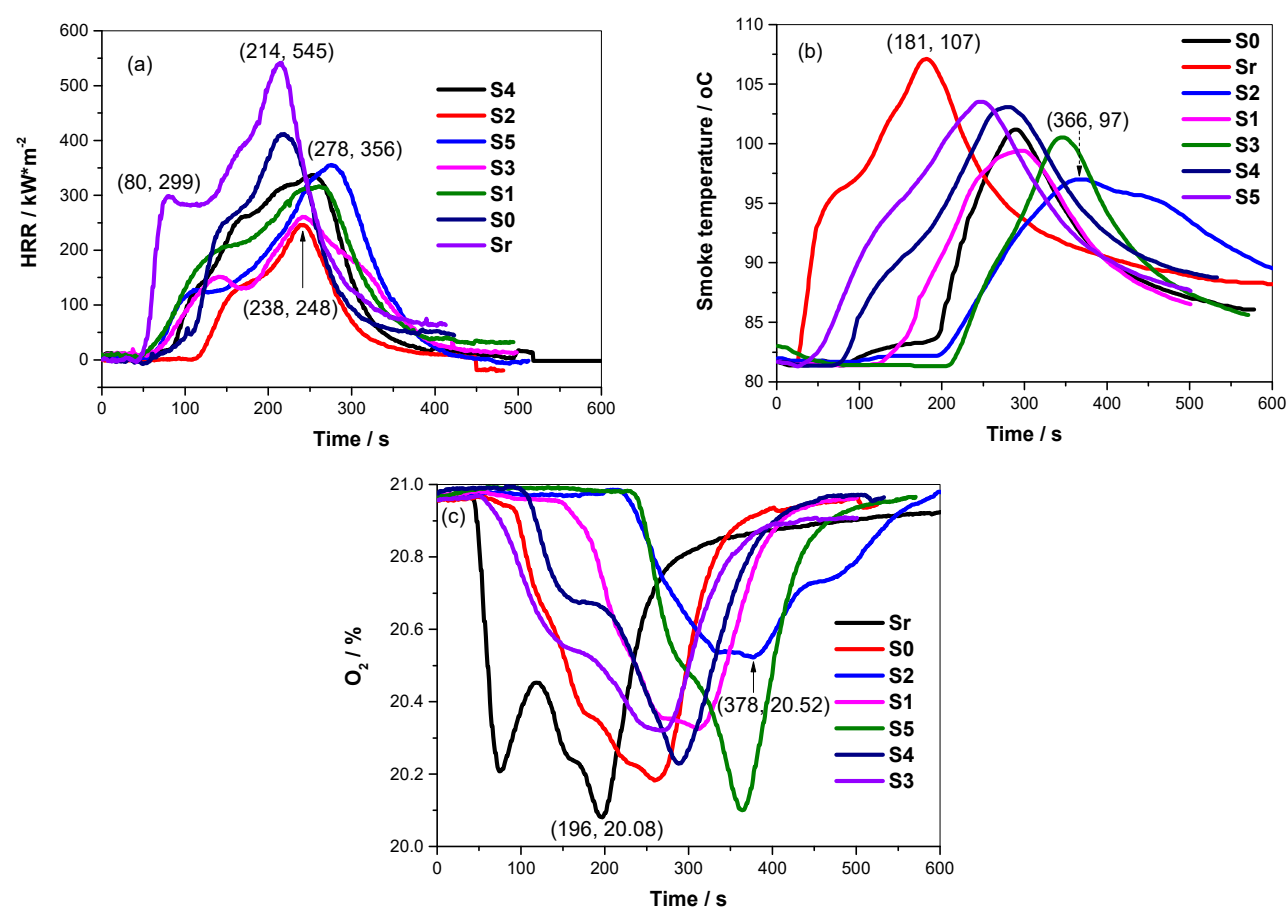

Figure 1. Real-time combustion parameters of samples including (a) heat release rate (HRR), (b) smoke temperature, and (c) $\mathrm{O}_{2}$ concentration.

Figure $1 \mathrm{~b}$ presents the smoke temperature of samples during the whole process of burning, the obvious "right shift" of the smoke temperature peak was examined, and the lowest peak of $97^{\circ} \mathrm{C}$ was located on S2 at $366 \mathrm{~s}$, while that of $\mathrm{Sr}$ was $107^{\circ} \mathrm{C}$ at $181 \mathrm{~s}$. The delayed and shrunk peak indirectly demonstrates that $\mathrm{S} 2$ with $1 \mathrm{wt} . \% \mathrm{NH}_{4} \mathrm{SCN}$ exerts the highest flame resistance. However, a reverse increase and "left shift" in the smoke temperature peak were observed when the content of $\mathrm{NH}_{4} \mathrm{SCN}$ exceeded 1 wt.\%, which is consistent with the results of HRR in Figure 1a. Moreover, the $\mathrm{O}_{2}$ concentration in exhaust gas of smoke tube takes on a similar tendency to that of the HRR, the highest $\mathrm{O}_{2}$ concentration peak of $20.52 \%$ appeared in $\mathrm{S} 2$ at $378 \mathrm{~s}$, while that of $\mathrm{Sr}$ was $20.08 \%$ at $196 \mathrm{~s}$ as shown in Figure 1c. Because the $\mathrm{O}_{2}$ is an essential element for the burning of samples, the higher $\mathrm{O}_{2}$-consumption implies fiercer combustion, $\mathrm{S} 2$ with the lowest $\mathrm{O}_{2}$-consumption corresponds to the slowest burning, which also confirms that an appropriate dosage of $\mathrm{NH}_{4} \mathrm{SCN}$ favors the enhancement of geopolymeric coatings effectively.

Table 2 shows an increase of $T_{\mathrm{b}}$ for the samples with $\mathrm{NH}_{4} \mathrm{SCN}$, but an enhancement of flame resistance was clarified. For S2, the FPI increased from 0.14 (S0) to $0.41 \mathrm{~s} \cdot \mathrm{m}^{2} \cdot \mathrm{kW}^{-1}$, and FGI dropped from $1.88(\mathrm{~S} 0)$ to $1.04 \mathrm{~kW} \cdot \mathrm{m}^{-2} \cdot \mathrm{s}^{-1}$, indicating an enhanced flame resistance [19]. It also implies that S2 holds a superior flame resistance than the others, therefore, an appropriate dosage of $\mathrm{NH}_{4} \mathrm{SCN}$ serves to improve the flame-retardant efficiency of geopolymeric coatings.

Table 2. Combustion parameters of samples tested by cone calorimeter (CC).

\begin{tabular}{|c|c|c|c|c|c|c|}
\hline Samples & TTI (s) & $T_{\mathrm{b}}(\mathrm{s})$ & $T_{\mathrm{p}}(\mathrm{s})$ & pHRR $\left(k W \cdot m^{-2}\right)$ & FPI $\left(s \cdot m^{2} \cdot k W^{-1}\right)$ & FGI $\left(\mathrm{kW} \cdot \mathrm{m}^{-2} \cdot \mathrm{s}^{-1}\right)$ \\
\hline $\mathrm{Sr}$ & 18 & 289 & 214 & 545 & 0.03 & 2.55 \\
\hline S0 & 58 & 298 & 219 & 411 & 0.14 & 1.88 \\
\hline S1 & 78 & 312 & 234 & 301 & 0.33 & 1.29 \\
\hline S2 & 102 & 356 & 238 & 248 & 0.41 & 1.04 \\
\hline S3 & 81 & 373 & 243 & 261 & 0.33 & 1.07 \\
\hline S4 & 59 & 342 & 252 & 343 & 0.17 & 1.36 \\
\hline S5 & 47 & 320 & 278 & 356 & 0.13 & 1.28 \\
\hline
\end{tabular}

TTI-time to ignite; $T_{\mathrm{b}}$ - time to the cessation of flaming; $\mathrm{pHRR}$ - peak heat release rate; $T_{\mathrm{p}}$ - time to $\mathrm{pHRR}$; FPI-fire perfomance index, FPI = TTI/Phrr; FGI-fire growth index, FGI $=\mathrm{pHRR} / T_{\mathrm{p}}$. 


\subsection{Morphologies}

\subsubsection{Macro-Morphology of Samples}

The cinereous geopolymeric coatings covered on the plywood are displayed in Figure 2a, no bubbling or peeling is observed, but efflorescence is obviously seen, due to the strong alkaline conditions derived from the alkali activators. It reveals the geopolymeric coatings could serve as primers rather than finishing coatings due to the whitening and non-transparency. With the increasing content of $\mathrm{NH}_{4} \mathrm{SCN}$, the phenomenon of efflorescence weakens as shown in Figure 2b, and the samples take on uniformly smooth surfaces in Figure 2c,d. However, a rough coating surface was observed for S4 with $2 \mathrm{wt} . \% \mathrm{NH}_{4} \mathrm{SCN}$ as shown in Figure 2e, the strands of coating appear for S5 in Figure 2f, due to the non-uniform dispersion and filming.
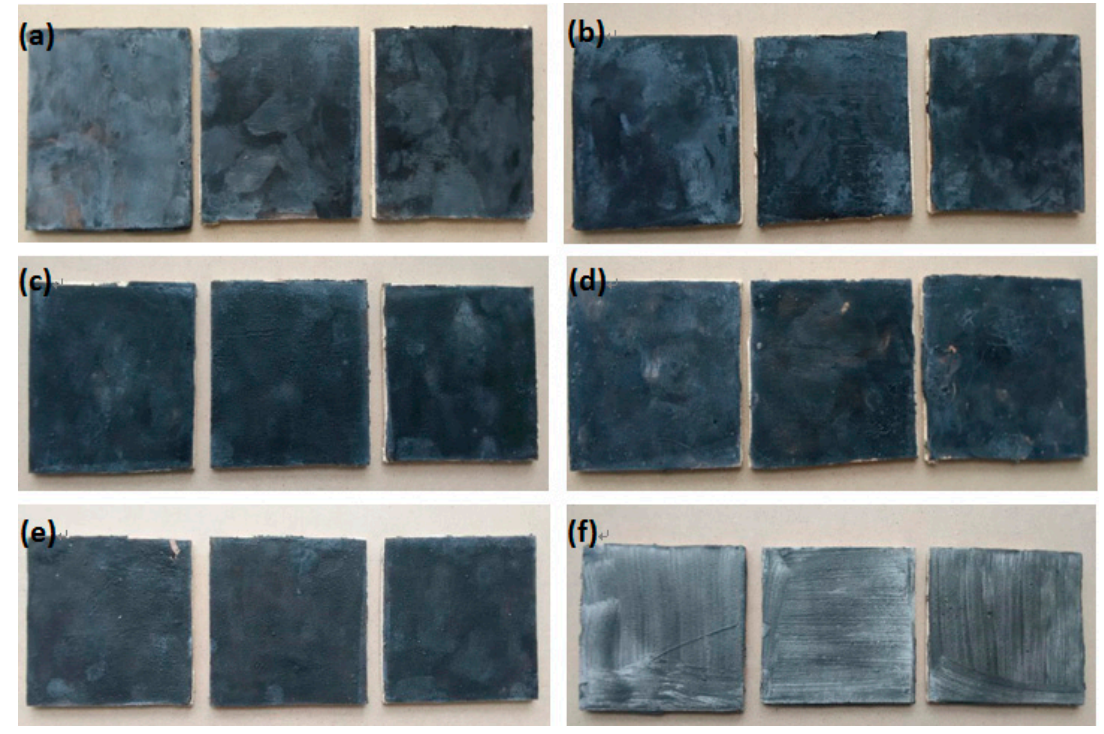

Figure 2. Appearance of specimens before combustion including (a) S0, (b) S1, (c) S2, (d) S3, (e) S4, (f) S5.

After combustion in the CC, a swollen siliceous layer was generated as shown in Figure 3, which protected the underlying plywood from burning effectively, Figure 3a presents a thinner and broken shielding layer. However, a gradually swelling intact layer presents with the increasing dosage of $\mathrm{NH}_{4} \mathrm{SCN}$ in Figure $3 \mathrm{~b}$, and Figure $3 \mathrm{c}$ takes on a continuous and uniform layer, corresponding to the improved flame resistance. But some pores are present in Figure 3d, which might be attributed to the escape of excess $\mathrm{NH}_{3}$ derived from the transformation of $\mathrm{NH}_{4} \mathrm{SCN}$, evidenced by the fish-scale feature as shown in Figure 3e. Moreover, non-uniform swelling-induced cracks spread rapidly for S5, with the increasing dosage of $\mathrm{NH}_{4} \mathrm{SCN}$, leading to a chipped and rough surface in Figure $3 \mathrm{f}$. This demonstrates that the flame resistance mainly depends on the formation of an intact siliceous shielding layer, due to its incombustibility and excellently thermal stability.

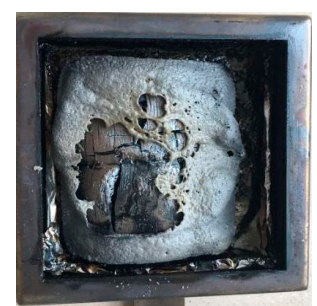

(a)

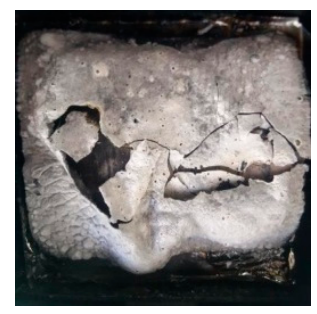

(b)

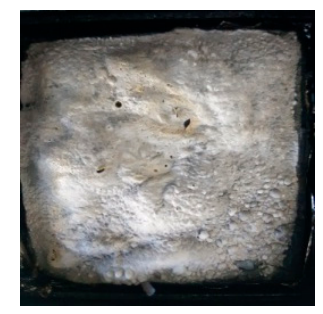

(c)

Figure 3. Cont. 


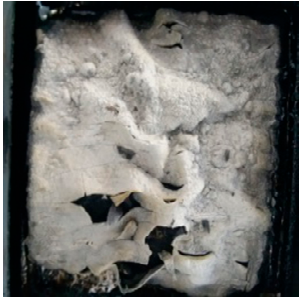

(d)

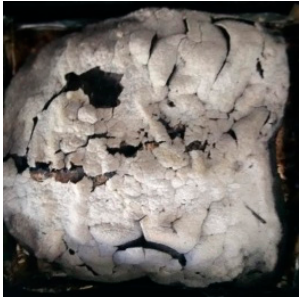

(e)

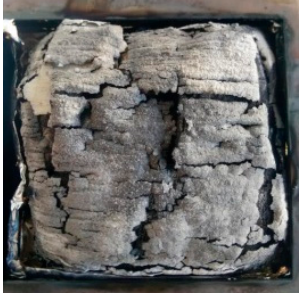

$(\mathbf{f})$

Figure 3. Appearance of specimens after combustion including (a) S0, (b) S1, (c) S2, (d) S3, (e) S4, (f) S5.

\subsubsection{Micro-Morphology after Combustion}

The amorphous spicules were dispersed on the matrix with many pores or holes as shown in Figure 4a. After doping $\mathrm{NH}_{4} \mathrm{SCN}$ into the coatings, a decrease in the volume of pores or holes was observed, presenting a continuous and uniform barrier layer as shown in Figure 4b. S2 exhibits a smoother, more homogeneous and continuous structure as shown in Figure 4c, compared with that of others. However, a lot of crystalline filaments and pores with an average pore diameter of approximately $5 \mu \mathrm{m}$ were observed as seen in Figure $4 \mathrm{~d}$, when the content of $\mathrm{NH}_{4} \mathrm{SCN}$ increased to 3 wt. $\%$, they might be the channels left by $\mathrm{NH}_{3}{ }^{-}$escaping.

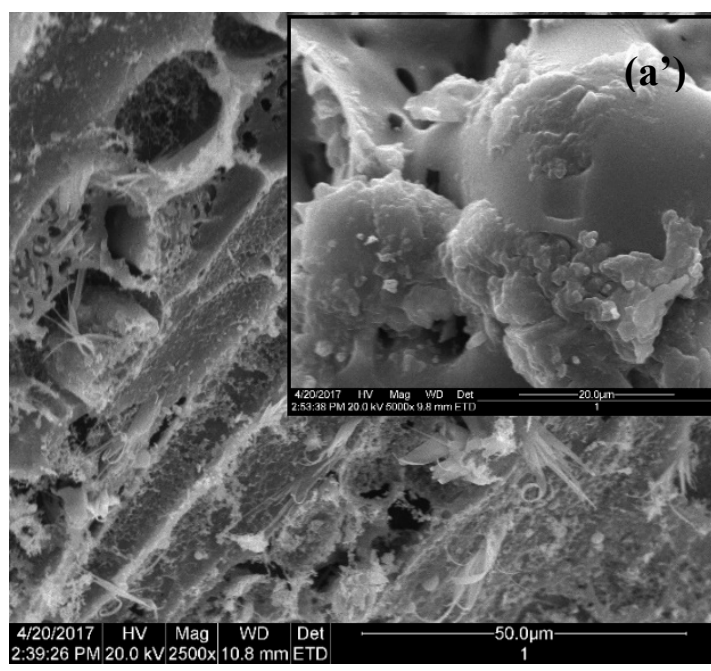

(a)

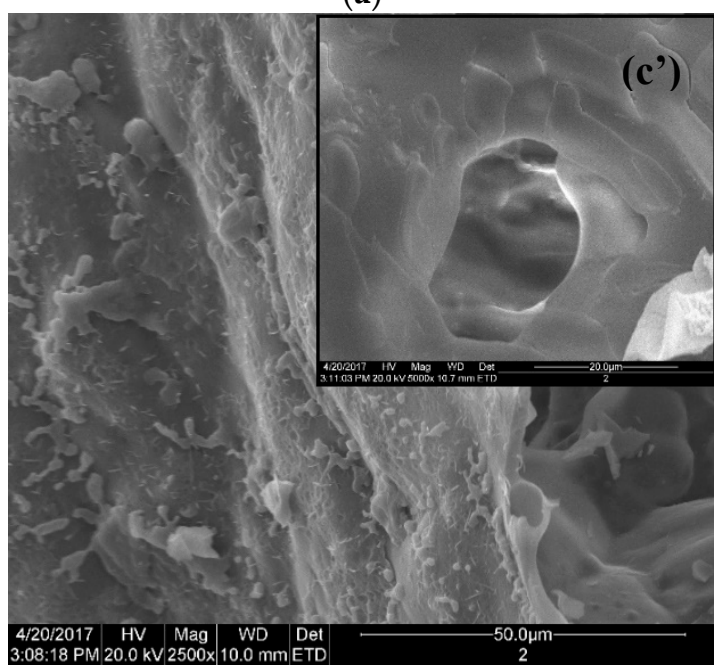

(c)

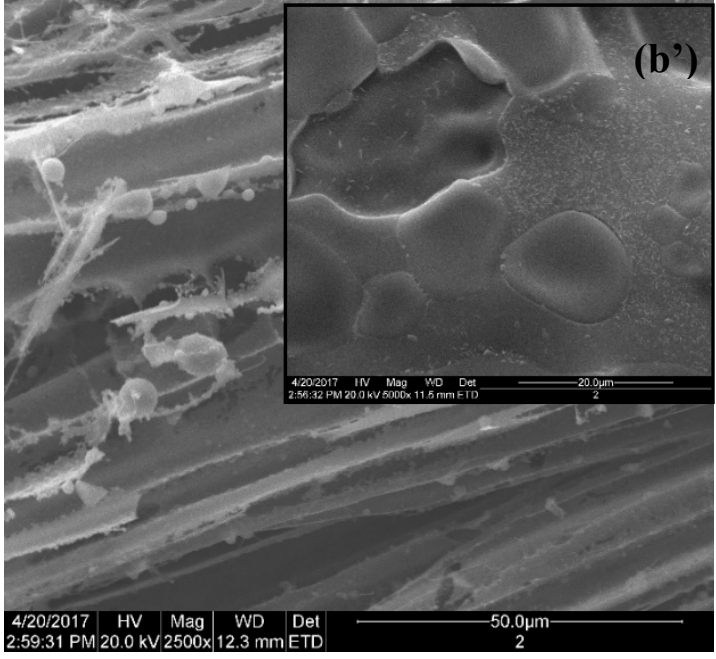

(b)

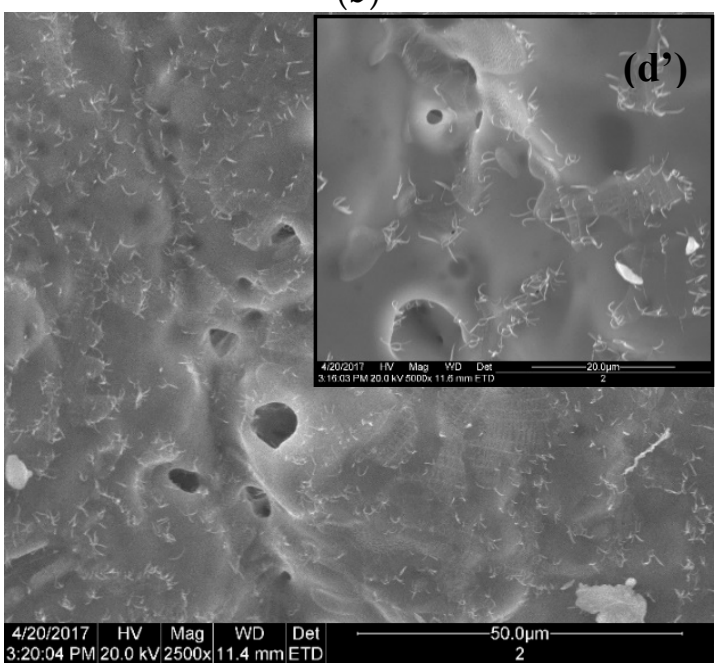

(d)

Figure 4. SEM images of specimens after combustion including (a) S0, (b) S1, (c) S2, and (d) S5 with

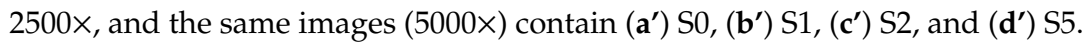




\section{3. $T G / D S C$}

The weight loss was essentially equal to approximately 15.5\% for both S2 and S5 as shown in Figure 5, the slight change in the weight loss indirectly determines that the doped $\mathrm{NH}_{4} \mathrm{SCN}$ completely dissolves or decomposes, rather than transforms into a complicated structure through insertion or linkage [20]. However, the weight loss temperature (WLT) increased from 78.5 to $82.2{ }^{\circ} \mathrm{C}$ with the increasing content of $\mathrm{NH}_{4} \mathrm{SCN}$. According to the TG-DTG method [21], the onset temperature changed slightly while the end-set temperature climbed from 96.5 to $102.9^{\circ} \mathrm{C}$ as shown in Figure $5 \mathrm{a}, \mathrm{b}$. Because the evaporation of free water occurs at $<105^{\circ} \mathrm{C}$, the increases in WLT and end-set temperature indicate that the doped $\mathrm{NH}_{4} \mathrm{SCN}$ slightly restrains the vaporization heat of water involved in the samples, due to strong interactions between $\mathrm{NH}_{4}{ }^{+}$and $\mathrm{H}_{2} \mathrm{O}$.
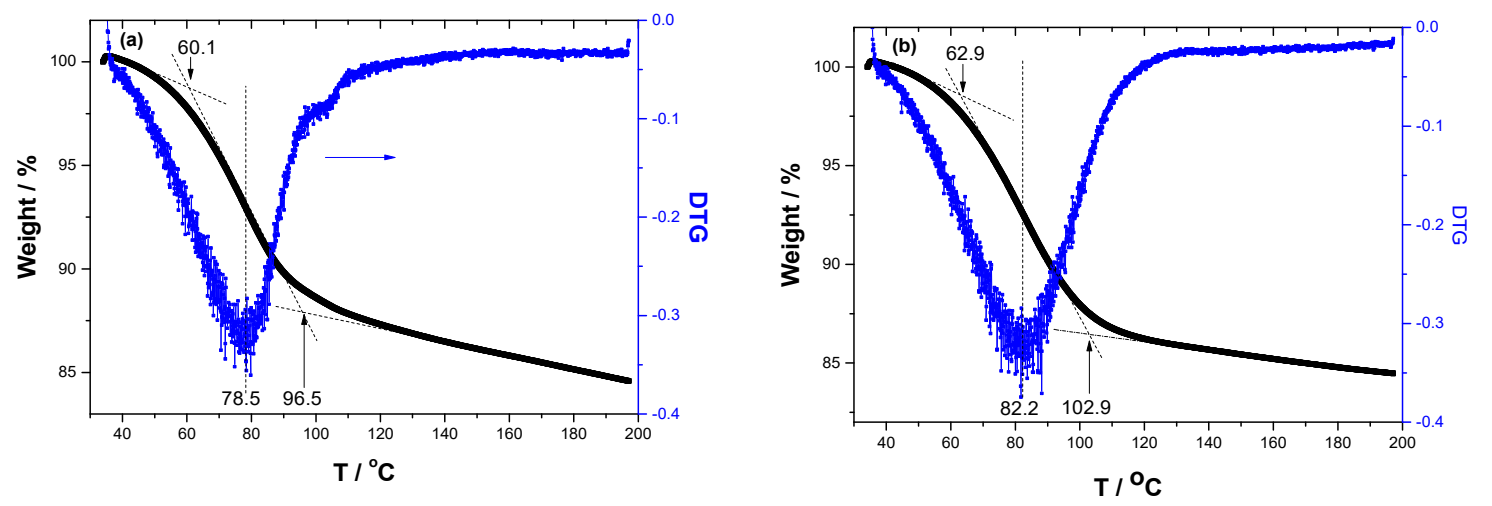

Figure 5. TG/DTG curves of samples including (a) S2 and (b) S5.

Moreover, the heat absorption of S5 decreased slightly and a tiny left-shift of the peak temperature occurred compared with that of S2 as shown in Figure 6. It has been reported that the transformation of $\mathrm{NH}_{4} \mathrm{SCN}$ into thiourea occurs at approximately $140{ }^{\circ} \mathrm{C}[22,23]$, no endothermic peak appeared at $140{ }^{\circ} \mathrm{C}$, implying that the $\mathrm{NH}_{4} \mathrm{SCN}$ reacted under strong alkaline conditions. Due to its high solubility and ionized $\mathrm{NH}_{4}{ }^{+}$, the prior reaction between $\mathrm{NH}_{4}{ }^{+}$and $\mathrm{OH}^{-}$occurs with heat released, leading to a slight decrease in absorption heat, evidenced by the shrunken area $\mathrm{h}_{\mathrm{S} 5}\left(224.1 \mathrm{~J} \cdot \mathrm{g}^{-1}\right)$ of the endothermic peak in comparison to $\mathrm{h}_{\mathrm{S} 2}\left(297.6 \mathrm{~J} \cdot \mathrm{g}^{-1}\right)$.

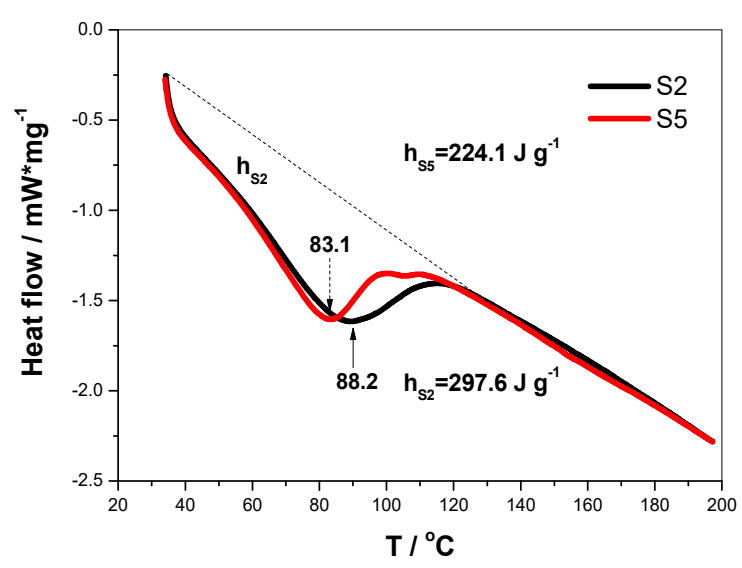

Figure 6. Heat flow of samples including S2 and S5.

\section{4. $X R D$}

Figure 7 mainly presents huge humps assigned to amorphous silicate at approximately $2 \theta=15^{\circ} \sim 30^{\circ}$. Small diffraction peaks superimposed on the hump corresponded to the poorly crystalline phases including tridymite $\left(\mathrm{SiO}_{2}\right.$, PDF No.: 14-0260), quartz $\left(\mathrm{SiO}_{2}\right.$, PDF No.: 46-1045), 
natrite $\left(\mathrm{Na}_{2} \mathrm{CO}_{3}\right.$, PDF No.: 37-0451), sodium sulfite $\left(\mathrm{Na}_{2} \mathrm{SO}_{3}\right.$, PDF No.: 37-1488), and sodium sulfate ( $\mathrm{Na}_{2} \mathrm{SO}_{4}$, PDF No.: 01-0990). However, the absence of peaks corresponding to thiocyanate determines complete dissolution or decomposition, which is in agreement with the finding of literature [24,25]. The obvious characteristic diffraction peaks of tridymite and quartz derive from the transformation of fumed silica. The natrite forms through the reactions shown in Equations (1)-(3), firstly the $\mathrm{NH}_{4} \mathrm{SCN}$ reacts with the $\mathrm{OH}^{-}$and produces $\mathrm{NH}_{3}, \mathrm{~S}^{2-}$, and $\mathrm{CO}_{3}{ }^{2-}$, following by the formation of sodium sulfite via oxidizing reaction between the $\mathrm{S}^{2-}$ and $\mathrm{O}_{2}$ derived from air, finally partial sodium sulfite is oxidized further and transfers into sodium sulfate. $\mathrm{SCN}^{-}$can transform into $\mathrm{S}^{2-}, \mathrm{CO}_{2}$, and $\mathrm{NH}_{4}{ }^{+}$under acid environment via a reduction reaction [24]. However, the hump of amorphous silicate covers the spectra of $\mathrm{Na}_{2} \mathrm{CO}_{3}, \mathrm{Na}_{2} \mathrm{SO}_{3}$, and $\mathrm{Na}_{2} \mathrm{SO}_{4}$, because of their low contents in XRD patterns.

$$
\begin{gathered}
\mathrm{NH}_{4} \mathrm{SCN}+4 \mathrm{OH}^{-}=2 \mathrm{NH}_{3} \uparrow+\mathrm{CO}_{3}{ }^{2-}+\mathrm{S}^{2-}+\mathrm{H}_{2} \mathrm{O} \\
2 \mathrm{~S}^{2-}+3 \mathrm{O}_{2}=2 \mathrm{SO}_{3}{ }^{2-} \\
2 \mathrm{SO}_{3}{ }^{2-}+\mathrm{O}_{2}=2 \mathrm{SO}_{4}{ }^{2-}
\end{gathered}
$$

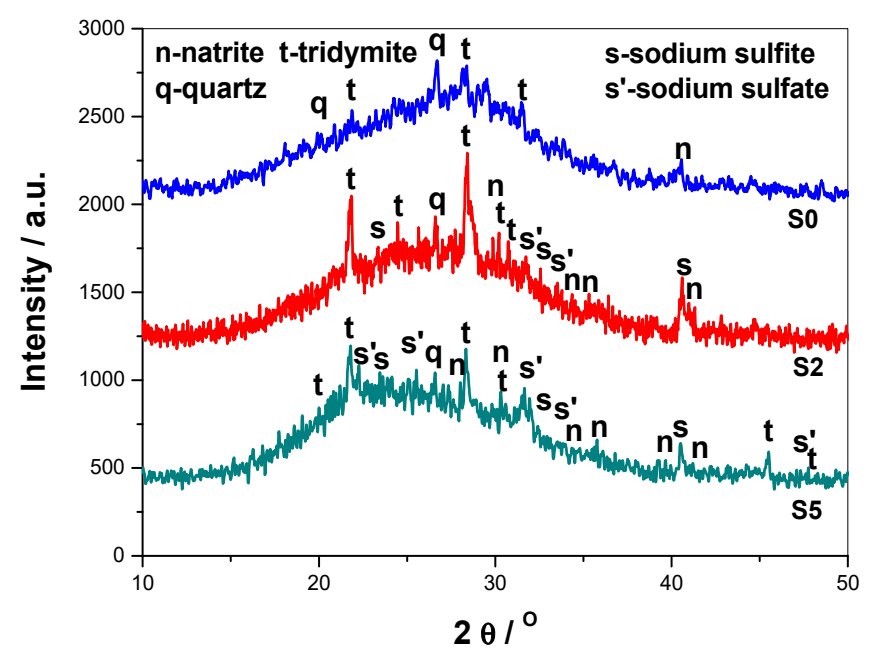

Figure 7. XRD of samples after combustion.

\section{Discussion}

It has been reported that mercerization increases the interfacial bonding strength between lignocellulosic fibers and organics [26-28], the alkaline condition facilitates removal of soluble components $[29,30]$, and, therefore, chemical bonding between the siliceous gel and plywood forms. Furthermore, $\mathrm{SCN}^{-}$is prone to associate with nonpolar surfaces due to its low charge density and weak-tightly bonding hydration shell [31], and the plywood surface mainly consists of nonpolar cellulose and hemicellulose, which prompts a strong adhesive property of geopolymeric coatings, favoring the more pronounced fireproof property.

On the other hand, it can be inferred that the improved flame resistance of geopolymeric coatings is attributed to the following factors according to the results of $\mathrm{CC}$ and XRD. Firstly, $\mathrm{NH}_{4} \mathrm{SCN}$ postpones the rising pHRR as a suitable $\mathrm{O}_{2}{ }^{-}$consuming reductant. $\mathrm{NH}_{4} \mathrm{SCN}$ with a melting temperature of $149.6^{\circ} \mathrm{C}$ can transform into thiourea at $140 \sim 180^{\circ} \mathrm{C}$ [22], the strong alkaline condition triggers the prior oxidizing reaction and the firing provides the conditions for the formation of sulfate, this implies that the phase change performance of $\mathrm{NH}_{4} \mathrm{SCN}$ is limited or inhibited, but the reducibility is beneficial for retarding flame-propagation by consuming $\mathrm{O}_{2}$. Secondly, $\mathrm{NH}_{4} \mathrm{SCN}$ mainly favors the formation of a continuous layer as a dopant for reinforcing the siliceous layer, due to its natural amorphousness [32], which facilitates its diffusion and migration in the amorphous geopolymeric coatings, and the formation of carbonate and sulfate prompts a continuous and compact siliceous layer as a barrier filler. Finally, 
$\mathrm{NH}_{4} \mathrm{SCN}$ suppresses the diffusion of heat and flame by releasing $\mathrm{NH}_{3}$ - the $\mathrm{NH}_{3}$ derives from two routes, one is the combination of $\mathrm{NH}_{4}^{+}$and $\mathrm{OH}^{-}$, the other is the transformation of $\mathrm{N}^{3-}$ in $\mathrm{SCN}^{-}$. The former mainly takes place during the process of preparation, leading to negligible flame resistance, but the latter possesses an obviously inhibiting effect during combustion.

However, flame resistance declines when the dosage of $\mathrm{NH}_{4} \mathrm{SCN}$ exceeds $1 \mathrm{wt} . \%$, this can be ascribed to the rapid increase in viscosity of coatings, evidenced by the non-uniform dispersion and filming, as well as the increase in WLT from TG. The coating is prone to fattening for S5, due to strong water-consuming hydrolysis of $\mathrm{NH}_{4} \mathrm{SCN}$, especially for the alkaline environment that accelerates and boosts the formation of $\mathrm{NH}_{3}$. The superfluous $\mathrm{SCN}^{-}$could transform into $\mathrm{CO}_{3}{ }^{2-}, \mathrm{SO}_{3}{ }^{2-}$, and $\mathrm{SO}_{4}{ }^{2-}$ according to the result of $\mathrm{XRD}$, which consumes $\mathrm{O}_{2}$ to delay the propagation of flames, evidenced by the gradual right-shift of $\mathrm{pHRR}$ with increasing $\mathrm{NH}_{4} \mathrm{SCN}$. However, the $\mathrm{O}_{2}$-consuming effect is weak (low content) because the formation of an intact and uniform shielding layer is of vital importance for flame retardancy. The thermal conductivity is remarkably decreased because of the discontinuous coating or film [33], which blocks heat conduction and charring of the hybrid coating during combustion, as well as the formation of swelling siliceous layers, leading to a chipped and rough surface.

Although this paper presents a cost effective and ecological geopolymeric coatings for flame-retarding plywood, an important issue to highlight is the interactions between $\mathrm{NH}_{4} \mathrm{SCN}$ and PDMS, EG, and other components. As seen from the charring mechanism on the carbon/siliceous layer, SEM only provides a final morphology, but a pyrolysis kinetic is essential to investigate the novel coatings. This work might be the first step toward preparing novel $\mathrm{NH}_{4} \mathrm{SCN}$-doped geopolymeric coatings for flame-retarding plywood as a primer, proposing a new pathway for meeting the sustainable demand of "end-of-waste". Furthermore, some deep problems remain in durability and chemical structure, which need to be analyzed and evaluated in detail.

\section{Conclusions}

To obtain an ecological, cost-effective, and high flame-retarding coating, a facilely prepared halogen-free flame-retardant coating was explored by mixing the alkali-activated fumed silica-based geopolymer with $\mathrm{PDMS}, \mathrm{EG}$, and $\mathrm{NH}_{4} \mathrm{SCN}$. Its flame resistance and microstructure were preliminarily investigated and the following conclusions were drawn.

- A novel $\mathrm{NH}_{4} \mathrm{SCN}$-modified geopolymeric coatings for flame-retarding plywood was prepared via a facile sol-gel method, and the optimal dosage of $\mathrm{NH}_{4} \mathrm{SCN}$ was determined as $1 \mathrm{wt} . \%$, evidenced by the highest FPI, the lowest FGI, and the pHRR dropping to $248 \mathrm{~kW} \cdot \mathrm{m}^{-2}$ with a $39.7 \%$ decrease.

- Microstructure analysis determined that moderate use of $\mathrm{NH}_{4} \mathrm{SCN}$ as a dopant is of importance for a uniform and continuous coating before combustion, which is beneficial for the formation of a smooth and intact swollen siliceous shielding layer during combustion. The enhancement of flame resistance mainly depends on the formation of a compact and continuous siliceous layer.

Author Contributions: Conceptualization, Y.W. and J.Z.; methodology, Y.W.; software, Y.W.; validation, Y.W.; formal analysis, Y.W.; investigation, Y.W.; resources, J.Z.; data curation, J.Z.; writing—original draft preparation, Y.W.; writing-review and editing, Y.W.; visualization, Y.W.; supervision, J.Z.; project administration, Y.W.; funding acquisition, Y.W.

Funding: This research was funded by the Natural Science Foundation of Shanxi Province, grant number 2018JQ5131.

Conflicts of Interest: The authors declare no conflict of interest.

\section{References}

1. Laoutid, F.; Lorgouilloux, M.; Bonnaud, L.; Lesueur, D.; Dubois, P. Fire retardant behaviour of halogen-free calcium-based hydrated minerals. Polym. Degrad. Stab. 2017, 136, 89-97. [CrossRef]

2. Dong, W.L.; Yoo, B.R. Advanced silica/polymer composites: Materials and applications. J. Ind. Eng. Chem. 2016, 38, 1-12. 
3. Fan, F.Q.; Xia, Z.B.; Li, Q.Y.; Li, Z. Effects of inorganic fillers on the shear viscosity and fire retardant performance of waterborne intumescent coatings. Prog. Org. Coat. 2013, 76, 844-851. [CrossRef]

4. Fufa, S.M.; Jelle, B.P.; Hovde, P.J. Effects of $\mathrm{TiO}_{2}$, and clay nanoparticles loading on weathering performance of coated wood. Prog. Org. Coat. 2013, 76, 1425-1429. [CrossRef]

5. Komnitsas, K.; Zaharaki, D. Geopolymerisation: A review and prospects for the minerals industry. Miner. Eng. 2007, 20, 1261-1277. [CrossRef]

6. Wang, Y.C.; Zhao, J.P. Comparative study on flame retardancy of silica fume-based geopolymer activated by different activators. J. Alloys Compd. 2018, 743, 108-114. [CrossRef]

7. Wang, Y.C.; Zhao, J.P. Facile preparation of slag or fly ash geopolymer composite coatings with flame resistance. Constr. Build. Mater. 2019, 203, 655-661. [CrossRef]

8. Navarro, L.; Gracia, A.D.; Colclough, S.; Browne, M.; Mccormack, S.J.; Griffiths, P.; Cabeza, L.F. Thermal energy storage in building integrated thermal systems: A review. Part 1. Active storage systems. Renew. Energy 2016, 88, 526-547. [CrossRef]

9. Lim, K.S.; Bee, S.T.; Sin, L.T.; Tee, T.T.; Ratnam, C.T.; Hui, D.; Rahmat, A.R. A review of application of ammonium polyphosphate as intumescent flame retardant in thermoplastic composites. Compos. Part B Eng. 2016, 84, 155-174. [CrossRef]

10. Pielichowska, K.; Pielichowski, K. Phase change materials for thermal energy storage. Prog. Mater. Sci. 2014, 65, 67-123. [CrossRef]

11. Li, L.; Wang, G.; Guo, C. Influence of intumescent flame retardant on thermal and flame retardancy of eutectic mixed paraffin/polypropylene form-stable phase change materials. Appl. Energy 2016, 162, 428-434. [CrossRef]

12. Xu, L.; Liu, X.; An, Z.; Yang, R. EG-based coatings for flame retardance of shape stabilized phase change materials. Polymer Degrad. Stab. 2019, 161, 114-120. [CrossRef]

13. Wang, Y.C.; Zhao, J.P. Preliminary study on decanoic/palmitic eutectic mixture modified silica fume-based geopolymeric coating for flame retardant plywood. Constr. Build. Mater. 2018, 189, 1-7. [CrossRef]

14. Woo, H.J.; Majid, S.R.; Arof, A.K. Dielectric properties and morphology of polymer electrolyte based on poly( $\varepsilon$-caprolactone) and ammonium thiocyanate. Mater. Chem. Phys. 2012, 134, 755-761. [CrossRef]

15. Wang, Y.C.; Zhao, J.P. Effect of graphene on flame retardancy of graphite doped intumescent flame retardant (IFR) coatings: Synergy or antagonism. Coatings 2019, 9, 94. [CrossRef]

16. Reaction-to-Fire Tests-Heat Release, Smoke Production and Mass Loss Rate; BS ISO 5660-1:2015; ISO Copyright Office: Geneva, Switzerland, 2015.

17. Fateh, T.; Rogaume, T.; Luche, J.; Richard, F.; Jabouille, F. Characterization of the thermal decomposition of two kinds of plywood with a cone calorimeter-FTIR apparatus. J. Anal. Appl. Pyrolysis 2014, 107, 87-100. [CrossRef]

18. Hirschler, M.M. Flame retardants and heat release: Review of traditional studies on products and on groups of polymers. Fire Mater. 2015, 39, 207-231. [CrossRef]

19. Wang, Y.C.; Zhao, J.P. Benign design and the evaluation of pyrolysis kinetics of polyester resin based intumescent system comprising of alkali-activated silica fume. Prog. Org. Coat. 2018, 122, 30-37. [CrossRef]

20. Zhang, Y.J.; Wang, Y.C.; Xu, D.L.; Li, S. Mechanical performance and hydration mechanism of geopolymer composite reinforced by resin. Mater. Sci. Eng. A 2010, 527, 6574-6580. [CrossRef]

21. Chen, Z.; Hu, M.; Zhu, X.; Guo, D.; Liu, S.; Hu, Z.; Xiao, B.; Wang, J.; Laghari, M. Characteristics and kinetic study on pyrolysis of five lignocellulosic biomass via thermogravimetric analysis. Bioresour. Technol. 2015, 192, 441-450. [CrossRef]

22. Losev, V.N.; Elsufiev, E.V.; Buyko, O.V.; Trofimchuk, A.K.; Horda, R.V.; Legenchuk, O.V. Extraction of precious metals from industrial solutions by the pine (pinus sylvestris) sawdust-based biosorbent modified with thiourea groups. Hydrometallurgy 2018, 176, 118-128. [CrossRef]

23. Zhang, C.Z.; Niu, M.X. Study on mechanism of isomerization between ammonium thiocyanate and thiourea. J. Mol. Struct. 2016, 1125, 643-648. [CrossRef]

24. Kulshrestha, N.; Chatterjee, B.; Gupta, P.N. Characterization and electrical properties of polyvinyl alcohol based polymer electrolyte films doped with ammonium thiocyanate. Mater. Sci. Eng. B 2014, 184, 49-57. [CrossRef]

25. Ichiba, M.; Sakai, J.; Doshida, T.; Takai, K. Corrosion reaction and hydrogen absorption of steel for prestressed concrete in a 20 mass\% ammonium thiocyanate solution. Scr. Mater. 2015, 102, 59-62. [CrossRef] 
26. Singh, R.; Shukla, A.; Tiwari, S.; Srivastava, M. A review on delignification of lignocellulosic biomass for enhancement of ethanol production potential. Renew. Sustain. Energy Rev. 2014, 32, 713-728. [CrossRef]

27. Fiore, V.; Bella, G.D.; Valenza, A. The effect of alkaline treatment on mechanical properties of kenaf fibers and their epoxy composites. Compos. Part B Eng. 2015, 68, 14-21. [CrossRef]

28. Ramesh, M. Kenaf (Hibiscus cannabinus L.) fibre based bio-materials: A review on processing and properties. Prog. Mater. Sci. 2016, 78-79, 1-92. [CrossRef]

29. George, M.; Chae, M.; Bressler, D.C. Composite materials with bast fibres: Structural, technical, and environmental properties. Prog. Mater. Sci. 2016, 83, 1-23. [CrossRef]

30. Hou, X.; Sun, F.; Yan, D.; Xu, H.; Dong, Z.; Li, Q.; Yang, Y. Preparation of lightweight polypropylene composites reinforced by cotton stalk fibers from combined steam flash-explosion and alkaline treatment. J. Clean. Prod. 2014, 83, 454-462. [CrossRef]

31. Grundl, G.; Müller, M.; Touraud, D.; Kunz, W. Salting-out and salting-in effects of organic compounds and applications of the salting-out effect of pentasodium phytate in different extraction processes. J. Mol. Liq. 2017, 236, 368-375. [CrossRef]

32. Pandi, D.V.; Selvasekarapandian, S.; Bhuvaneswari, R.; Premalatha, M.; Monisha, S.; Arunkumar, D.; Junichi, K. Development and characterization of proton conducting polymer electrolyte based on PVA, amino acid glycine and $\mathrm{NH}_{4} \mathrm{SCN}$. Solid State Ion. 2016, 298, 15-22. [CrossRef]

33. Barletta, M.; Guarino, S.; Rubino, G.; Trovalusci, F.; Tagliaferri, V. Environmentally friendly wooden-based coatings for thermal insulation: Design, manufacturing and performances. Prog. Org. Coat. 2014, 77, 701-711. [CrossRef]

(C) 2019 by the authors. Licensee MDPI, Basel, Switzerland. This article is an open access article distributed under the terms and conditions of the Creative Commons Attribution (CC BY) license (http://creativecommons.org/licenses/by/4.0/). 